\title{
Delusions of grandeur
}

Delusions, although commonplace in psychiatric practice, defy rational explanation. A useful working hypothesis, however, is that in the deluded psychotic the logic of waking life is violated by forces from the unconscious. From a launching-pad deep down in the unconscious, fantasies, hitherto reserved for dreams or nightmares, take off into the mental stratosphere shattering reality as they ascend.

Delusions of grandeur fit this hypothesis very neatly. They are all fantastical, but what gives each its separate identity are the pre-psychotic proclivities of the individual concerned. The avaricious become millionaires, billionaires, or trillionaires; the ambitious assume dominion over the earth and the heavens, including these days, the moon; the snob walks with Kings and Emperors, or assumes these roles himself.

I am reminded of a rare and appropriate example of just this sort of delusional grandiosity. Sam was a Cockney born and bred. He was descended from a long line of costermongers who for generations had hawked fruit from barrows in the London Bridge area. Sam had another characteristic: he was the essential gaffer, far more accustomed to giving orders than to recetving them. In whatever sphere he operated he was the boss.

Unfortunately for him, Sam had at some point in his life contracted syphilis which had either been inadequately treated, or not treated at all. In the year 1952 a combination of serological, neurological, and psychiatric evidence left absolutely no doubt that Sam had developed general paralysis of the insane. Horton Hospital, Epsom, where I was then employed, specialised in the treatment of Sam's malady and his admission there was duly arranged. Malaria-induced hyperpyrexia was the treatment of choice.

About this time there was another fever in the air - Coronation Fever, which as the great day approached increased to near delirium. On 'C' day minus one I happened to meet Sam, now convalescent, in the hospital grounds. June or no June, Sam wore his customary rig: flat cap, muffler, waistcoat, and gold-albert. We chatted and not surprisingly the subject of conversation switched to the morrow's great event. I was going up to London to see the show, wasn't I, he asked. "No," I replied. "Not much point in going without having a seat." "A seat," retorted Sam, his voice seared with contempt. "A seat for you, guv," he went on, removing for the first time his thumbs from the arm-holes of his waistcoat and wagging his right forefinger under my nose. "Just leave it to me, guv. I'll get yer a bleeding thronel"

Henry R. Rollin, Emeritus Consultant, Horton Hospital, Epsom

Other contributions to this column are welcome for consideration. 